\title{
Rocuronium-induced anaphylaxis: a case report
}

\author{
Kanako Takahashi ${ }^{{ }^{*}}$ (D), Satoru Tanaka', Masanori Watanabe ${ }^{1}$ and Michiaki Yamakage ${ }^{2}$
}

\begin{abstract}
Background: Neuromuscular blocking agents are frequently a cause of anaphylaxis that occurs in the perioperative period, and a skin prick test is an examination for definite diagnosis.

Case presentation: We report our experience of a patient with rocuronium-induced anaphylaxis who was scheduled to undergo open-heart surgery. After induction of anesthesia, anaphylaxis was suspected because the patient's blood pressure decreased, airway pressure increased, and skin flushing and edema were observed on her neck and arms. With rapid treatment, good progress was seen without complications. About 5 weeks later, skin prick tests were performed for rocuronium and vecuronium. She was positive for rocuronium and negative for vecuronium. Seven weeks after anaphylaxis, vecuronium was used for the surgery and she had no symptoms that indicated anaphylaxis. The operation was completed uneventfully.
\end{abstract}

Conclusion: We experienced a case of anaphylaxis caused by rocuronium. After a definite diagnosis had been made by a skin prick test, safe anesthesia management was possible using vecuronium during the reoperation.

Keywords: Rocuronium, Vecuronium, Anaphylaxis, Skin prick test

\section{Background}

The frequency of perioperative anaphylaxis is thought to be about one case in 10,000-20,000 worldwide [1]. According to the Medical Accident Investigation and Support Center of the Japan Medical Safety Research Organization, in recent statistics on population dynamics, the number of deaths due to anaphylaxis is about 50 to 80 per year and the most common cause is medicine (about 20 to 40 deaths per year) [2]. The drugs that most frequently cause anaphylaxis during general anesthesia are neuromuscular blocking agents (NMBAs) [1]. A case of multiple cross-reactivities to various NMBAs has been reported [3]. A skin test is used for a definite diagnosis of anaphylaxis [1].

We experienced a case of anaphylaxis caused by rocuronium. After a definite diagnosis had been made by a skin prick test, safe anesthesia management was possible using vecuronium during surgery that was performed 7 weeks later.

\footnotetext{
* Correspondence: kyokui090080@gmail.com

1Department of Anesthesiology, Oji General Hospital, 3-4-8 Wakakusacho,

Tomakomai City, Hokkaido 053-8506, Japan

Full list of author information is available at the end of the article
}

\section{Case presentation}

Informed consent was obtained from the patient for publication of this case report and any accompanying images. A 74-year-old woman (body weight, $48 \mathrm{~kg}$; height, $148 \mathrm{~cm}$ ) without a history of drug allergy was scheduled to undergo open-heart surgery. She was taking oral medication for high blood pressure and atrial fibrillation. After hospitalization due to heart failure, severe mitral regurgitation and tricuspid regurgitation were found by echocardiography, and mitral valve replacement, tricuspid annuloplasty, and the maze procedure for atrial fibrillation were scheduled. Laboratory data were unremarkable except NT-proBNP 1920 pg/ml.

General anesthesia was induced with $4 \mathrm{mg}$ of midazolam, $200 \mu \mathrm{g}$ of fentanyl and $50 \mathrm{mg}$ of rocuronium.

Tracheal intubation was performed uneventfully. Immediately after inserting a probe for recording a transesophageal echocardiogram, increase in airway pressure up to 40 $\mathrm{cmH}_{2} \mathrm{O}$, reduction in blood pressure, and skin flushing and edema on her neck and arms were confirmed. Hate rate was $120 \mathrm{bpm}$ or more and systolic arterial blood pressure fell to less than $60 \mathrm{mmHg}$ and a low level persisted despite repeated administration of phenylephrine. An electrocardiogram showed no significant ST-T change in 
atrial fibrillation. With a possible diagnosis of anaphylaxis, we started chest compression and administered $1 \mathrm{mg}$ adrenaline and $1000 \mathrm{mg}$ methylprednisolone approximately $2 \mathrm{~min}$ after the onset of symptoms. In consideration of a possible latex allergy, the probe for a transesophageal echocardiogram was removed together with the probe cover, and the urinary catheter was also removed and replaced with a latex-free one. Following the insertion of a catheter into the right internal jugular vein, we started a continuous infusion of noradrenaline at 0.1 $\mu \mathrm{g} / \mathrm{kg} / \mathrm{min}$. Although blood pressure and heart rate gradually stabilized approximately $30 \mathrm{~min}$ after starting treatment, the planned surgery was suspended. She remained orotracheally intubated and was transferred to the intensive care unit.

No further anaphylactic reaction or other complications occurred, and she was extubated the next day. Two days later, the results of drug-induced lymphocyte stimulation tests (DLSTs) for rocuronium and midazolam were negative.

Five weeks after anesthesia, skin prick test was conducted for rocuronium and vecuronium, following a method reported previously [1]. In brief, undiluted rocuronium and vecuronium (10 and $4 \mathrm{mg} / \mathrm{ml}$, respectively), histamine (positive control) and normal saline (negative control) were prepared. One drop of the allergen was placed on the forearm flexion side, and the skin was punctured through the allergen with a $26 \mathrm{G}$ needle. After $15 \mathrm{~min}$, the diameter of the wheal (mean value of the longest diameter and the diameter perpendicular to the midpoint) was measured, and more than half of the positive control and $3 \mathrm{~mm}$ or more of the negative control were judged as positive [4]. The diameters of the wheals were $9 \mathrm{~mm}$ for histamine, $8 \mathrm{~mm}$ for rocuronium, and $0 \mathrm{~mm}$ for vecuronium and normal saline, and the results were therefore positive for rocuronium and negative for vecuronium (Fig. 1).

Surgery was performed seven weeks after anaphylaxis. General anesthesia was induced with midazolam, fentanyl, and vecuronium and was maintained with sevoflurane, vecuronium, and intermittent fentanyl. Surgery was completed uneventfully.

\section{Discussion}

It has been reported that even without a history of general anesthesia, some people have IgE antibodies of NMBAs, suggesting the involvement of a quaternary ammonium structure common to muscle relaxants [1]. In our case, anaphylaxis occurred in the first general anesthesia.

Since the surgery was not emergent, it was suspended until definite identification of the antigen for anaphylaxis. Among various methods for diagnostic investigation, in vivo skin tests including prick and intradermal reaction tests remain the gold standard for detection of IgE-dependent allergies; these tests are best done after a delay of 4 to 6 weeks [1], when the antibody recovers to a sufficient level. We detected rocuronium, but not vecuronium, as an antigen by prick tests 5 weeks after the onset of anaphylaxis. On the other hand, a DLST 2 days after anaphylaxis was negative for rocuronium, probably due to its high false-negative ratio, particularly in the acute phase [5].

In our case, since a definite diagnosis was obtained by the skin prick test, no further examination was done, but a basophil activation test (BAT), which has been reported to have high levels of sensitivity and specificity as an in vitro examination, was also considered [6]. A limitation of this study is the lack of measurements of plasma histamine

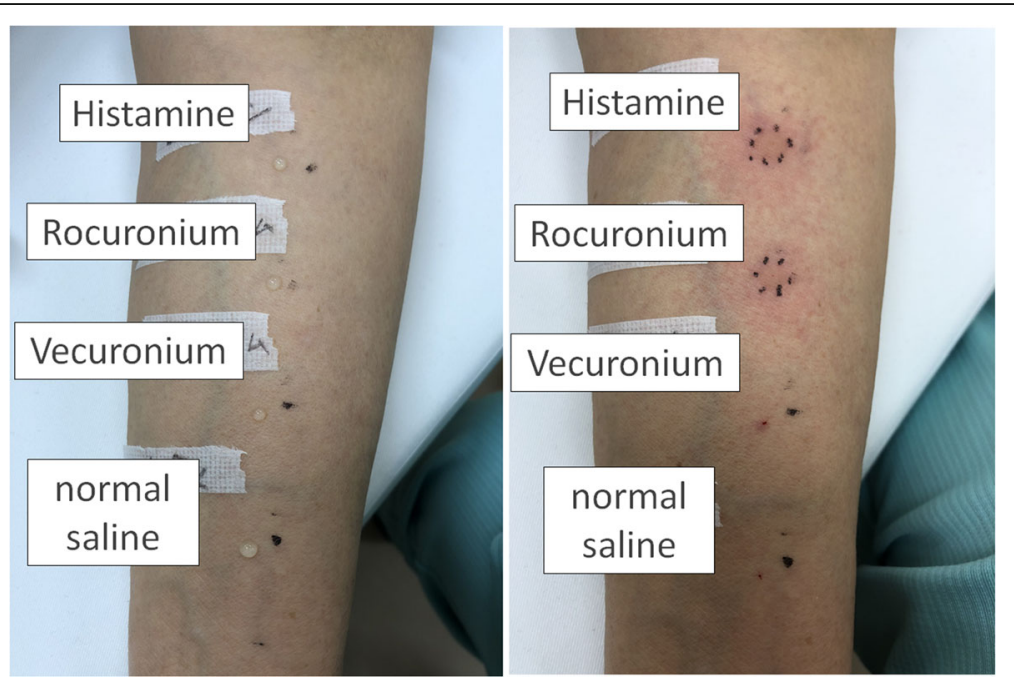

Fig. 1 Skin prick test. From the top, in the order of histamine, rocuronium, vecuronium, and normal saline. The figure on the left is before puncturing, and the figure on the right is $15 \mathrm{~min}$ after puncture. Wheals are surrounded by black dots at histamine and vecuronium 
concentration and serum tryptase concentration immediately after the onset of anaphylaxis $[1,7]$.

According to the guidelines of the Japanese Society of Allergology, intramuscular injection of adrenaline is the first choice for the treatment of anaphylaxis [8]. Perioperative guidelines in several countries recommend intravenous injection, but there is no consensus regarding the intravenous dose [1]. In our case, since the anaphylactic shock was severe and the carotid artery became palpable, we administered $1 \mathrm{mg}$ adrenaline intravenously.

\section{Conclusion}

We experienced a case of anaphylaxis caused by rocuronium. After a definite diagnosis had been made by a skin prick test, safe anesthesia management was possible using vecuronium during the operation. BAT has been recognized as a promising tool for in vitro diagnosis of allergy or other hypersensitivity reactions.

\section{Abbreviations}

BAT: Basophil activation test; DLST: Drug-induced lymphocyte stimulation test; NMBA: Neuromuscular blocking agent

\section{Acknowledgements}

Not applicable

\section{Authors' contributions}

$\mathrm{KT}$ and AW participated in the anesthetic management. KT drafted the manuscript. ST and MY supervised the manuscript drafting. All authors read and approved the final manuscript.

\section{Funding}

The authors declare that they have no funding.

Availability of data and materials

Not applicable due to patient privacy concerns.

\section{Ethics approval and consent to participate}

Not applicable

\section{Consent for publication}

Informed consent was obtained from the patient for publication of this case report and any accompanying images.

\section{Competing interests}

The authors declare that they have no competing interests.

\section{Author details}

1Department of Anesthesiology, Oji General Hospital, 3-4-8 Wakakusacho, Tomakomai City, Hokkaido 053-8506, Japan. ²Department of Anesthesiology, Sapporo Medical University School of Medicine, Minami 1-Jo Nishi 17-chome, Chuo-ku, Sapporo City, Hokkaido 060-8543, Japan.

Received: 3 June 2019 Accepted: 28 November 2019

Published online: 06 December 2019

\section{References}

1. Mertes PM, Malinovsky JM, Jouffroy $L$, and the Working Group of the SFAR and SFA and Aberer W, Terreehorst I, Brockow K, Demoly P, for ENDA and the EAACI Interest Group on Drug Allergy. Reducing the risk of anaphylaxis during anesthesia: 2011 updated guidelines for clinical practice. J Investig Allergol Clin Immunol 2011;21(6):442-453.

2. Medical Accident Investigation and Support Center Japan Medical Safety Research Organization. Analysis of deaths related to the complications of "Anaphylaxis with injection". 2018. https://www.medsafe.or.jp/uploads/ uploads/files/teigen-03.pdf. Accessed 1 March 2019.
3. Oh YJ, Lee HJ. Multiple cross-reactivity to several types of neuromuscular blocking agents in a patient with rocuronium anaphylaxis. Korean J Anesthesiol. 2013;65:473-4.

4. Mertes PM, Laxenaire MC, Lienhart $A$, and the working group for the SFAR, Aberer W, Ring J, Pichler WJ, Demoly P, for ENDA and the EAACl interest group on drug hypersensitivity. Reducing the risk of anaphylaxis during anesthesia: guidelines for clinical practice. J Invest Allergol Clin Immunol. 2005;15(2):91-101.

5. Sugihara T, Koda M, Okamoto T, Miyoshi K, Matono T, Hosho K, Okano J, Isomoto H, Tsutsumi R, Ehara Y. The usefulness of second drug-induced lymphocyte stimulation tests (DLST). Kanzo. 2016;57:571-6.

6. Decuyper II, Mangodt EA, Van Gasse AL, Claesen K, Uyttebroek A, Faber M, Sabato V, Bridts CH, Mertens C, Hagendorens MM, De Clerck LS, Ebo DG. In vitro diagnosis of immediate drug hypersensitivity anno 2017: potentials and limitations. Drugs R D. 2017:17(2):265-78.

7. Laroche D, Gomis P, Gallimidi E, Malinovsky JM, Mertes PM. Diagnostic value of histamine and tryptase concentrations in severe anaphylaxis with shock or cardiac arrest during anesthesia. Anesthesiology. 2014;121:272-9.

8. Japanese Society of Allergology. Anaphylaxis guideline. 2014. https:// anaphylaxis-guideline.jp/. Accessed 1 March 2019.

\section{Publisher's Note}

Springer Nature remains neutral with regard to jurisdictional claims in published maps and institutional affiliations.

\section{Submit your manuscript to a SpringerOpen ${ }^{\circ}$ journal and benefit from:}

- Convenient online submission

- Rigorous peer review

- Open access: articles freely available online

High visibility within the field

- Retaining the copyright to your article

Submit your next manuscript at $>$ springeropen.com 